\title{
PERTUNJUKAN KESENIAN BETAWI MILENIAL
}

\author{
Steven $^{1)}$, Suryono Herlambang ${ }^{2)}$ \\ 1) Program Studi S1 Arsitektur, Fakultas Teknik, Universitas Tarumanagara, steven.ta@stu.untar.ac.id \\ 2) Program Studi S1 Arsitektur, Fakultas Teknik, Universitas Tarumanagara, suryonoh@ft.untar.ac.id
}

\begin{abstract}
Abstrak
Marunda adalah kelurahan di kecamatan Cilincing, Jakarta Utara. Merupakan daerah di Jakarta yang penduduknya masih melestarikan rumah tradisional Betawi. Seni dan Budaya asli penduduk Jakarta atau Betawi yang berada di Cilincing dapat dilihat mereka sebagian masi menggunakan bahasa Betawi dan wisatawan dapat menyaksikan pertunjukan Betawi atau rumah kebaya, tetapi sayangnya mereka tidak memiliki satu tempat yang menaung mereka untuk melestarikan kebudayaan Betawi itu sendiri. Kebudayaan Betawi yang mulai terlupakan dan tersingkir disebabkan perkembangan Jakarta yang pesat menjadi pusat perekonomian dan banyak orang dari berbagai daerah suku ras dan budaya yang masuk ke Jakarta secara bersamaan dan secara tidak sadar menyingkirkan kebudayaan asli Jakarta yaitu Betawi, pelestarian budaya Betawi sangatlah di perlukan untuk identitas kota Jakarta maupun sebagai salah satu pelestarian budaya di Indonesia yang patut dipertahankan. Pengusulan program 'Pertunjukan Kesenian Betawi Milenial' memiliki tujuan mengangkat kembali kebudayaan Betawi untuk tujuan pariwisata menonjolkan identitas kota Jakarta, menaikan dan mengembangkan kawasan Marunda sebagai lokasi Tradisional Betawi dan menghidupkan kawasan Mauara Angke dari segi wisata dan perekenomian kawasan, membangun pusat kesenian Betawi di kawasan Betawi Pesisir dan mewakili wajah utama Jakarta dari sektor kebudayaan. Pengalaman wisatawan yang akan dibuat belajar sambil bersenang-senang sambil belajar tentang kebudayaan Betawi dengan konsep yang baru dengan unsur teknologi dan melakukan interaksi antara pemain dan pengunjung untuk meberikan kesan yang berbeda dari petunjukan kesenian lain yang sudah ada mereka hanya memportontonkan tanpa melakukan interaksi kepada penonton dan dapat dinikmati semua kalangan. Nantinya bangunan kesenian Betawi ini diharapkan akan memajukan dan meningkatkan perekonomian warga sekitar.
\end{abstract}

Kata kunci: betawi, kebudayaan milenial, wisata

\begin{abstract}
Marunda is a village in the Cilincing sub-district, North Jakarta. It is an area in Jakarta where residents still preserve traditional Betawi houses. Art and Culture of the residents of Jakarta or Betawi in Cilincing can be seen as they still use the original traditional Betawi language and tourists can witness traditional Betawi performances or kebaya houses, however, they unfortunately do not have personal place of their own to preserve Betawi culture itself. Betawi culture began to be forgotten and eliminated due to the rapid development of Jakarta as a center of economy. It is also caused by people from various racial and cultural regions who entered Jakarta simultaneously and unconsciously removed Jakarta's native culture, namely Betawi. It is necessary to preserve Betawi culture as it is the identity of Jakarta and one of the cultural preservations in Indonesia that should be maintained. The proposal for the 'Betawi Millennial Art Show' program aimed to revive Betawi culture for tourism purposes, highlighting the identity of the city of Jakarta, raising and developing the Marunda area as a Betawi Traditional location and reviving the Muara Angke region in terms of regional tourism and economy wise, building Betawi arts centers in the Betawi region Coastal and represent the core factor of Jakarta from the cultural sector. Tourists will experience learning and having fun while learning about Betawi culture with the new concepts that includes technological elements and interacting between players and visitors to give an impression that is different from other existing art shows that only provides potraying but no interaction between the audience and this new concept can certainly be enjoyed by all groups. Eventually, this building of Betawi art is expected to advance and improve the economy of the surrounding community.
\end{abstract}

Keywords: betawi, culture, millenial, tourism 


\section{PENDAHULUAN}

\section{Latar Belakang}

Jumlah penduduk di Jakarta mencapai 10 juta jiwa yang tecatat dalam Badan Pusat Statistik Provinsi DKI Jakarta, Jakarta menjadi tujuan utama bagi masyarakat Indonesia untuk mengadu nasib. Jakarta Pusat merupakan salah satu kota administrasi di pusat DKI Jakarta yang merupakan pusat dari pemerintahan provinsi dan juga nasional selain menjadi pusat pemerintahan Jakarta Pusat juga berfungsi sebagai pusat kegiatan bisnis, perdagangan dan jasa serta kawasan utama dari pengembangan infrastruktur. Jakarta bisa dikatkan sebagai pusatnya Indonesia karena yang tinggal di jakarta hampir dari semua daerah di Indonesia baik dari Sabang sampai Merauke. Jakarta Pusat sendiri memiliki luas 48,17 $\mathrm{km} 2$, dengan kondisi topografi yang relatif datar dan secara administratif dibagi menjadi 8 Kecamatan, 44 Kelurahan, 394 RW dan 4662 RT.

Jakarta sebagai ibu kota memeliki daya tarik sebagai tempat untuk mencari penghasilan sangat memikat pendatang baru dari berbagai daerah di Indonesia dan mengklaim sebagai warga Jakarta dari perkiraan sekitar 68.500 pendatang baru, sebanyak 60 persen diprediksi tinggal di Jakarta. Persaingan hidup yang timbul akibat penduduk yang datang dari berbagai daerah dan suku akan membuat budaya dan kepercayaan yang berkembang di Jakarta menjadi bermacam-macam dan secara tidak sadar melupakan kebudayaan asli Jakarta yaitu Betawi yang terselisih atas dinamika dari berbagai macam budaya yang masuk ke Jakarta.

Suku Betawi adalah suku bangsa di Indonesia yang penduduknya umumnya bertempat tinggal di Jakarta dan merupakan suku asli dari Jakarta. Sejumlah pihak berpendapat bahwa suku Betawi berasal dari hasil kawin-mawin antar etnis dan bangsa pada masa lalu, tetapi suku Betawi pada zaman sekarang sudah mulai tersingkir akibat perkembangan dan pesatnya kota Jakarta, suku Betawi mengelami penggusuran pemukiman warga di pusat kota memaksa mereka pindah ke pinggiran Jakarta. Warga asli Betawi yang tinggal di Jakarta tidak sedikit tercatat sekitar 2.310.587 Jiwa menempati urutan kedua setelah suku Jawa dan mereka tersebar di lima wilayah kota.

Kebudayaan Betawi merupakan bagian dari budaya nasional dan merupakan aset bangsa, maka keberadaanya perlu di jaga, dilestarikan dan dikembangkan sehingga berperan dalam upaya menciptakan budaya yang memiliki jati diri. Namun kebudayaan Betawi sudah sedikit yang di lestarikan salah satunya keberadaan sanggar seni Betawi di Jakarta sangat memperhatinkan hanya puluhan sanggar seni Betawi yang bertahan di ibu kota itupun tidak terlalu di perhatikan oleh permerintah dan masyarakat lainnya padahal waktu zaman 80an kesenian Betawi sangat dilestarikan di Jakarta semua kalangan masyarakat pasti mengetahui kebudayaan lenong, silat, makanan adat dan ondel-ondel.

Seni tari tradisional Betawi yang merupakan wahana eskpresi seni dari masyarakat sesuai dengan tempat ia berasal, yaitu masyarakat Betawi. Sebagai suatu bentuk ekspresi seni, tarian tradisional Betawi memiliki arti penting karena merupakan sarana bagi masyarakat pendukungnya untuk mengekspresikan diri di hadapan masyarakat. Seni tari tradisional Betawi, sebagaimana seni tari dari suku-suku lainnya di Indonesia, merupakan bagian dari suatu sistem representasi sekaligus suatu bentuk aksi. Keanekaragaman yang terdapat di dalam seni tari tradisional Betawi menunjukkan bahwa masyarakat pendukungnya adalah masyarakat yang kaya dengan aspirasi seni sesuai dengan asal-usul mereka yang pada mulanya ialah orang-orang yang datang dari berbagai penjuru nusantara dan Asia.

Berdasarkan sejarah perkembangannya, tari tradisional Betawi memiliki perbedaan masing-masing, baik dari segi pengaruh kebudayaan lain maupun masyarakat yang mengembangkannya. Tari tradisional Betawi yang berkembang pada saat itu adalah tari Cokek, tari Topeng, tari Blenggo, tari Sambrah, tari Pencak Silat, tari Uncul, dan tari Zapin. Bersamaan dengan itu muncul pula tari-tari kreasi baru 
Dengan keadaan ini pemerintah DKI Jakarta tidak tinggal diam untuk melestarikan kebudayaan Betawi yang terlupakan salah satunya adalah menetapkan festival palang pintu sebagai festival tahunan yang dilaksanakan di jalan Kemang Raya, belum lama ini cagar budaya Betawi juga dibuka di Setu Babakan,Jakarta Selatan di objek wisata yang berada di perkampungan Betawi, upaya pemerintahan melestarikan kebudayaan Betawi salah satunya mematenkan seni budaya Betawi sebagai warisan budaya negara Indonesia.

Pemerintah Daerah dalam Pelestarian Kebudayaan Betawi yakni: menumbuh kembangkan partisipasi dan kreativitas masyarakat menumbuh kembangkan dan meningkatkan kesadaran masyarakat Jakarta terhadap Pelestarian Kebudayaan Betawi melakukan koordinasi antar lembaga pemerintah, masyarakat, dan dunia usaha dalam upaya Pelestarian Kebudayaan Betawi dan mengkoordinasikan pelaksanaan pelestarian kebudayaan Betawi dengan daerah sekitarnya. Untuk melaksanakan tugas, Pemerintah Daerah mempunyai wewenang untuk menetapkan kebijakan serta strategi Pelestarian Kebudayaan Betawi pada kebijakan melakukan pembinaan dan pengawasan pelaksanaan kegiatan Pelestarian Kebudayaan Betawi menetapkan kawasan kebudayaan Betawi dan Memfasilitasi penyelenggaraan Pelestarian Kebudayaan Betawi yang diselenggarakan masyarakat Betawi.

\section{Rumusan Masalah}

- Bagaimana cara melestarikan kebudayaan Betawi yang sudah mulai punah secara menyeluruh dan untuk pelestarian zaman sekarang dan zaman yang akan datang di ibukota Jakarta?

- Bagaimana mengenalkan kebudayaan Betawi kepada masyarakat Jakarta yang sudah banyak mengenal kebudayaan bermacam-macam yang masuk ke kota Jakarta dan saling berselisih satu sama lain?

\section{Tujuan penelitian}

- Mengangkat kembali kebudayaan Betawi untuk tujuan pariwisata dan menonjolkan identitas kota Jakarta.

- Menaikan dan membangun daerah Marunda, Cilincing sebagai lokasi Betawi Pesisir dan menghidupkan kawasan Muara Angke selama 24 jam.

- Membangun pusat kesenian Betawi di kawasan Betawi Pesisir dan mewakili wajah utama dari sektor kebudayaan.

\section{Manfaat Penelitian}

- Menjadikan kawasan Marunda sebagai kawasan pariwisata yang dikenal sebagai daerah pelestarian Betawi pesisir dikenal oleh penduduk Jakarta maupun luar Jakarta.

- Meningkatkan perekonomian, kesejahteraan warga sekitar Marunda dengan manfaatkan pariwisata kebudayaan Betawi yang dilestarikan.

- Menguatkan kembali identitas Jakarta yang sesungguhnya dan dapat mewakili wajah utama Jakarta yang diperlihatkan sebagai ibukota.

\section{Problematika Desain Penelitian \\ Perkotaan}

- Intensitas Bangunan

- Aksesibilitas Menuju Tapak.

- Kepadatan Penduduk

- Peruntukan, Jaringan dan Utilitas

Lingkungan

- Pengaturan Parkir dan Ruang Terbuka

- Potensi Lingkungan dan Kondisi Lingkungan

- Pengaturan Sirkulasi, Pencapaian Tapak 


\section{Bangunan}

- Penyesuaian Bangunan dan Benuk Kebudayaan

- Pengolohan Bentuk Massa, Penampilan Bangunan dan Perlengkapan Bangunan

- Panggung, Lighting dan Teknologi

\section{Kegiatan}

- Sirkulasi Kegiatan

- Penggabungan Berbagai Kegiatan

\section{METODE}

Penelitian berpusat pada kawasan Marunda sebagai kawasan terkaji yang memiliki potensi dan identitas sebagai kawasan pariwisata kebudayaan Betawi di kota Jakarta. Hal ini didasarkan oleh sektor kependudukan warga asli Betawi yang tinggal di pesisir dan sejarah yang berkaitan antara Betawi dan Marunda. Mengidentifikasi dimensi arsitektural, meliputi luasan dan persenan pembagian ruang, nebganalisa keasaan lingkungan sekitar, fasilitas yang dapat dimanfaatkan dan sebagainya sebagai acuan penempatan pariwisata.

Dalam metode penelitian menggunakan metode riset dengan pendekatan realitas. Dengan datang langsung ke lokasi untuk melihat keadaan di lapangan secara langsung, observasi dan melakukan wawancara dengan warga sekitar untuk mengumpulkan data-data yang berkaitan dengan kebudayaan Betawi dan juga keadaan lokasi tidak hanya metode lapangan yang digunakan pemanfaatan buku-buku dan juga internet yang berhubungan dengan penelitian yang ajan di kerjakan di manfaatkan untuk tujuan mengambil informasi secara menyuluruh.

Dalam pengerjaan metode penelitian terdapat hasil-hasil yang telah di dapat sebegai berikut.

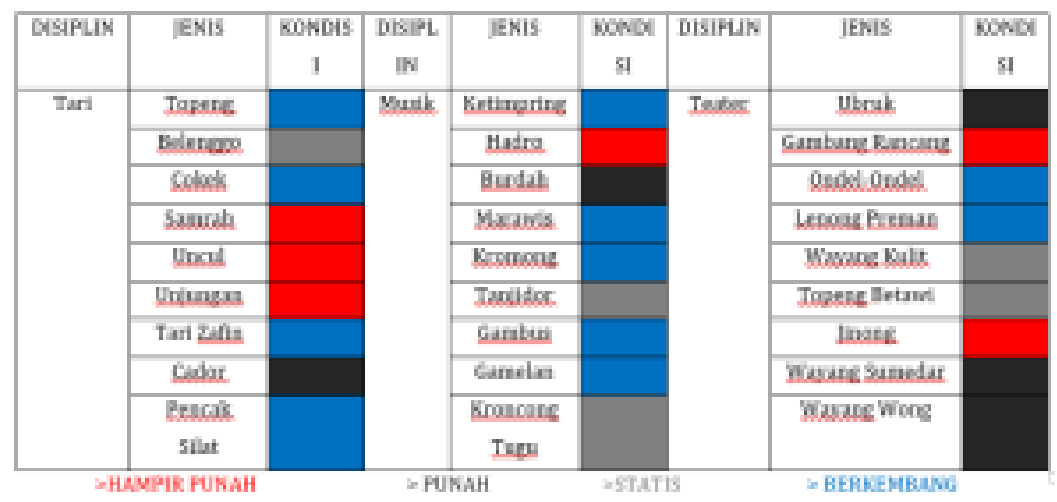

Gambar 1. Kondisi Perunjukan Seni Betawi

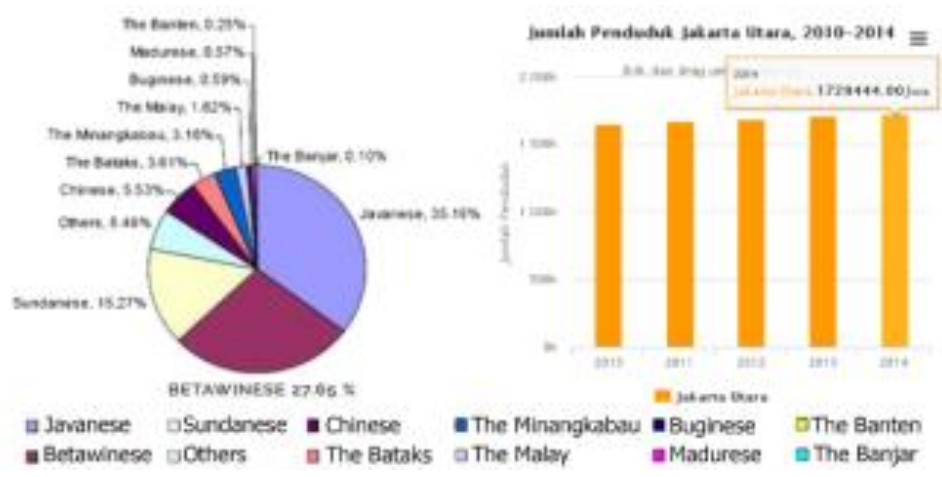

Gambar 2. Persebaran Etnis di Jakarta Sumber: Wikipedia 


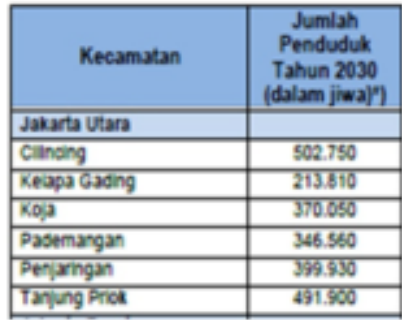

\begin{tabular}{|c|c|c|c|}
\hline NO & KELURAHAN & JUMLAH PENOUDUK & RW/RT \\
\hline 1 & Kelurahan Sukapura & 26.246 jiwa & $10 \mathrm{RW} / 98 \mathrm{RT}$ \\
\hline 2 & Kelurahan Rorotan & $26.867 \mathrm{jiwa}$ & $11 \mathrm{RW} / 116 \mathrm{RT}$. \\
\hline 3 & Kelurahan Marunda & 14.421 jwa & $9 \mathrm{RW} / 74 \mathrm{RT}$ \\
\hline 4 & Kelurahan Clincing & $33.026 \mathrm{jiwa}$ & $10 \mathrm{RW} / 129 \mathrm{RT}$. \\
\hline 5 & Kelurahan Semper Timur & $28.928 \mathrm{jiwa}$ & $10 \mathrm{RW} / 97 \mathrm{RT}$. \\
\hline 6 & Kelurahan Semper Barat & $61.899 \mathrm{jww}$ & $17 \mathrm{RW} / 235 \mathrm{RT}$ \\
\hline 7 & Kelurahan Kali Baru & $46.097 \mathrm{jiwa}$ & $14 \mathrm{RW} / 171 \mathrm{RT}$. \\
\hline
\end{tabular}

Gambar 3. Kepadatan Penduduk Marunda

Sumber: www.bps.go.id

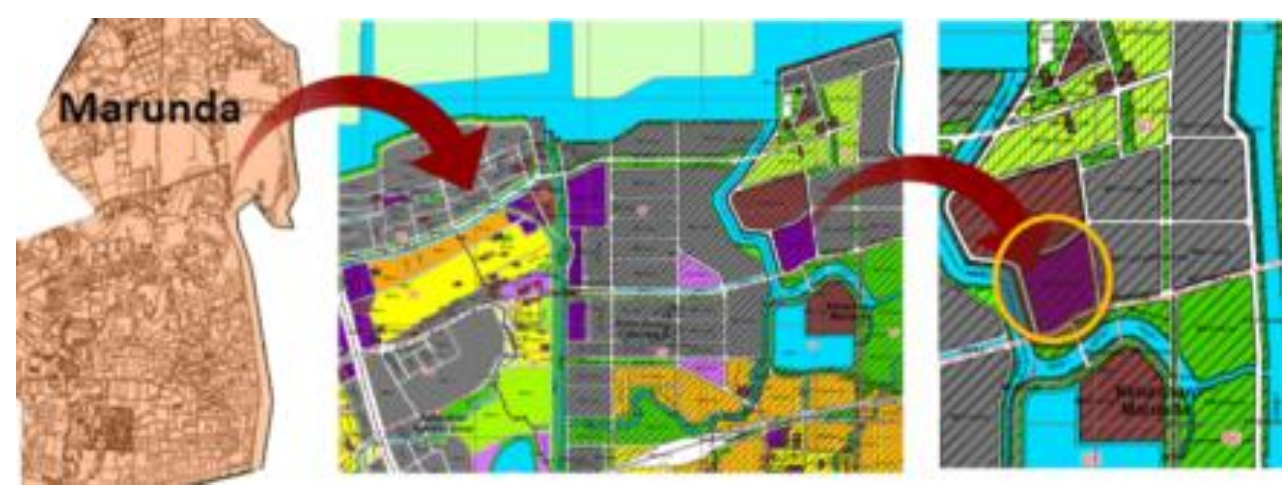

Gambar 4. Lokasi Site di Marunda

Sumber: Tata Ruang Jakarta

Kependukan kawasan Marunda yang tergolong signifikan dari era Betawi sampai sekarang. Hal ini memperlihatkan bahwa banyak orang asli Betawi yang masi menetap di Marunda yang terkenal dengan daerah si Pitung.

\begin{tabular}{|c|c|c|c|c|c|c|c|c|c|c|c|}
\hline KELURAHAN & BLOK & SUBBLCK & ZONA & $\begin{array}{l}\text { SUB } \\
\text { 20NA }\end{array}$ & IDSubelok & KOB & KLB & $K B$ & KOH & KTB $\pi$ & PIP PSI. \\
\hline IWRRNOA & 01 & $M$ & 2ONG INOUSTR DANPEROULANGAN & 11 & $0700911 a b c$ & f & 010 & 7 & 0 & 0 & $\Phi$ KP \\
\hline IWRPNOA & 01 & 010 & 20NA PERKANTORAN PEROAGGAGGN OAN LASA & K2 & $070002 a b e$ & 50 & 200 & 4 & 35 & \$1 & T KP \\
\hline
\end{tabular}

Gambar 5. Data Peruntukan

Sumber: Tata Ruang Jakarta

Pada site di Marunda yang terletak di jalan Marunda Makmur, dengan peruntukan campuran dan industri kawasan Marunda, pada tapak atau site memiliki KDB:50 KLB :2.00 KB:4 $\mathrm{KDH}: 35 \mathrm{KTB}: 50$ dengan luas lahan $7.000 \mathrm{~m}^{2}$ dengan keadaan lahan masi kosong dan memiliki akses transportasi umum yang mudah untuk menuju site selain itu juga memiliki jalan akses yang dekat dengan destinasi wisata Rumah Si Pitung yang bisa dikatakan sebagai icon Betawi di Marunda.

\section{DISKUSI DAN HASIL}

\section{Architectural Tourism}

Buku yang ditulis oleh Jam Spetch ini membahas bagaimana peran dan dampak arsitektur terhadap suatu negara atau kota. Architectural Tourism sangat penting untuk membangun suatu kota hubungan timbal balik antara praktek modern pariwisata dan lingkungan binaan tak terpisahkan sejak dulu bahkan menjangkau persepsi itu sendiri, untuk membangun tourism architecture ada unsur penting yang dibutuhkan untuk mendukung wilayah tersebut seperti: 
1.Attraction yaitu daya tarik, 2.Amenities yaitu fasilitas, 3.Accomodation yaitu akomodasi, 4.Acces yaitu akses, 5.Atmosphere yaitu suasana. Sebuah kota sejatinya akan selalu menarik pengunjung dari berbagai kalangan termasuk turis, ada 3 klasifikasi kota yang dikunjungi oleh turis:Resort Cities, Tourist-Historical Cities, Converted Cities dan kota-kota akan membuat suatu special event/contmporary architecture.

Dalam arsitektur simbolik menjadi salah satu aspek bagi turis tidak hanya menjadi sarana iklan seperti Spinx menjadi simbol budaya dan sejarah dan mendatangkan banyak turis dengan gambar dan simbol yang mempunyai makna tertentu menjadi penting karena turis akan lebih menghargai gambar visual yang tertanam oleh simbol, berbicara mengenai simbol dan fotografi peran arsitektur sangat penting karena rata rata wisatawan mencari destinasi yang photogenic dan peran arsitektur sangat penting dalam sebuah objek foto dan menjadi pemandangan yang berbeda bagi turis, turisme selalu melibatkan tontonan karena pentingnya visual ddan pariwisata selalu memperlihatkan tontonan seperti bangunan yang spektakuler biasa dimanipulasi dengan WOW factor, arsitektur bukan hanya bagian integral branding dan sebaliknya tetapi telah menjadi inti dari pemasaran lingkungan itu sendiri,arsitektur juga harus fleksibel agar dapar beradaptasi dengan perubahan dan menunjukan radikal perbedaan dan semacamnya.

\section{The Bilbao Effect : How Frank Gehry's Gunggenheim Started A Global Craze}

The Bilbao Effect - Artikel yang ditulis oleh Rowan Moore ini membahas tentang bagaimana keberhasilan revolusi industri kota Bilbao membangun suatu bangunan dan juga kawasan untuk meningatkan perekonomian kota tersebut dengan banyaknya kunjungan yang datang dan menjadi terkenal itu semua karena peran arsitektur terhadap kota yang merancang dan mendesain seperti Frank Gehry yang memberikan pengaruh besar pada Museum Bilbao Guggenheim.

Pada abad ke-20 setelah revolusi industri kota Bilbao menjadi kota yang berkembang pesat tetapi pada akhir abad ke-20 kota Bilbao diambang kebangkrutan karena area industri yang berpindah ke pusat peran pemerintah menetapakan strategi untuk membangun kota tersebut dengan memfokuskan pembangunan ke arah seni dan pariwisata, pada tahun 1991 pemerintah daerah ingin membangun sebuah museum di kota Bilbao lalu terpilihlah Frank 0. Gehry sebagai arsiteknya dan mengatahkan kota itu membutuhkan Sydney Opera House untuk meningkatkan perekonomian kota dan bertahan hidup Dengan dana mencapai US \$ 89.000.000, akhirnya dibangunlah Museum Bilbao Gunggenheim dan dinimati pada tahun 1997 dan pada saat itu pendapatan pariwisata kota Bilbao meningkat pesat.

Dengan pesatnya pariwisata di kota Bilbao menjadikannya pusat perekonomian daerah, Hanya dalam tiga tahun, pendapatan daerah dapat mengembalikan modal pembangunan museum. Dalam 12 tahun, pengunjung museum mencapai lebih dari 600.000 jiwa, dan membuat Bilbao menjadi destinasi utama di wilayah Basque. Kesuksesan Bilbao Guggenheim Museum menjadi fenomena yang kini dikenal dengan nama The Bilbao Effect.

Artikel tentang The Bilbao Effect menceritakan bagaimana arsitektur dan kota memiliki ketergantungan satu sama lain terutama dalam hal pariwisata, karya Gehry memiliki suatu dampak bagi kota Bilbao dan juga seperti karya Jorn Utzon terhadap kota Sydney, pada fenomena tentang The Bilbao Effect menjadi inspirasi bagi kota-kota dan juga arsitektur yang terkenal dan banyak di contohkan oleh kota-kota lain, Gehry juga mengatakan bagaimana peran arsitektur yang sangat penting dalam pembangunan agar dapat dinikmati oleh berbagai kalangan dengan berbagai cara untuk menunjukan suatu identitas kota.

\section{Analisis menggunakan pendekatan kontekstual}

Arsitektur Kontekstual adalah sebuah metode perancangan yang mengkaitkan dan menyelaraskan bangunan baru dengan karakteristik lingkungan sekitar, gerakan pengusung paham arsitektur kontekstual sendiri muncul dari penolakan dan perlawanan terhadap 
arsitektur modern sebagai ikon gaya internasional yang antihistoris, monoton, bersifat industrialisasi, dan kurang memerhatikan kondisi bangunan lama di sekitarnya dengan itu arsitek harus mejaga atau memanfaatkan keindahan/potensi alam letak keberadaanya dengan nilai-nilai lokal sekitarnya serta mengidealkan kapabilitasnya melalui bagunan yang dirancang dengan hubungan keterkaitan dengan lingkungan dan memberikan keuntungan antara tapak dan rancangan yang akan dibangun.

\section{Kawasan Marunda Jakarta Utara}

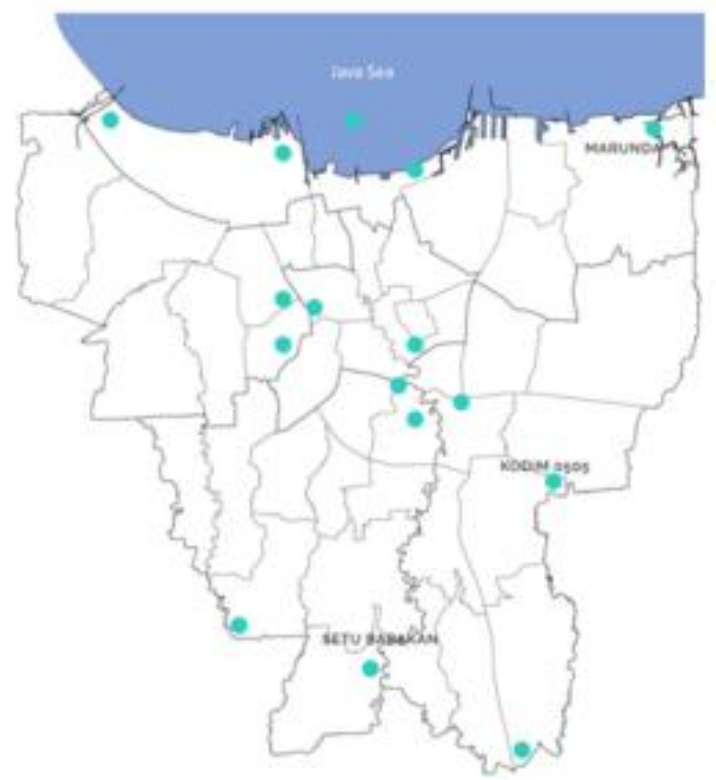

Gambar 6. Pesebaran Wilayah Betawi

Pemetaan Persebaran Wilayah Betawi, yang terdiri dari :

- Dadap

- Muara Baru

- Sunda Kelapa

- Kampung Japad

- Kampung Bandan

- Ancol

- Tj Priok

- Marunda

- Glodok

- Krukut

- Sawah Besar, dan lain-lain

Dari semua kawasan yang berada di DKI Jakarta hanya kawasan Jakarta Selatan di Setu Babakan dan kawasan Jakarta Timur di Kodim 0505 Jatinegara yang dikembangkan tetapi pada kawasan tersebut kurangnya fasilitas, event dan hiburan yang memadai untuk warga sekitar dan wisatawan yang berkunjung, Marunda menjadi salah satu kawasan yang berada di Jakarta Utara dengan rata-rata masyarakat Betawi yang masi menetap dan mempunyai potensi untuk dijadikan wisata kawasan hiburan pertunjukan kesenian Betawi. 

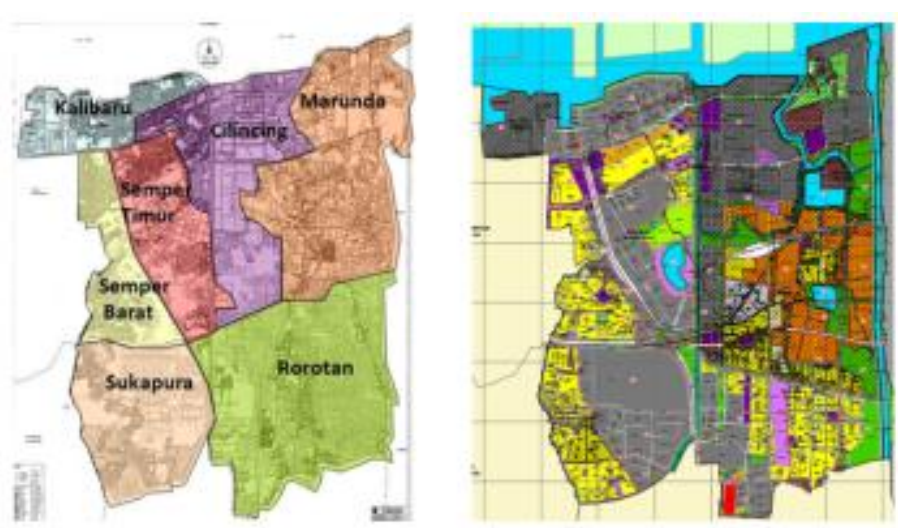

Gambar 7. Lokasi Marunda

Sumber: Tata Ruang Jakarta

Bedasarkan pengelolaan tata ruang, kawasan Cilincing-Marunda diperuntukan untuk menjadi kawasan Industry dan perumahan vertical ketinggian sedang, namun terdapat juga peruntukan lain untuk melengkapi kebutuhan kawasan tersebut menurut zonasi ruang seperti sub zona perkantoran, sub zona perdagangan dan jasa, sub zona campuran dan sub zona prasarana rekreasi dan olahraga.

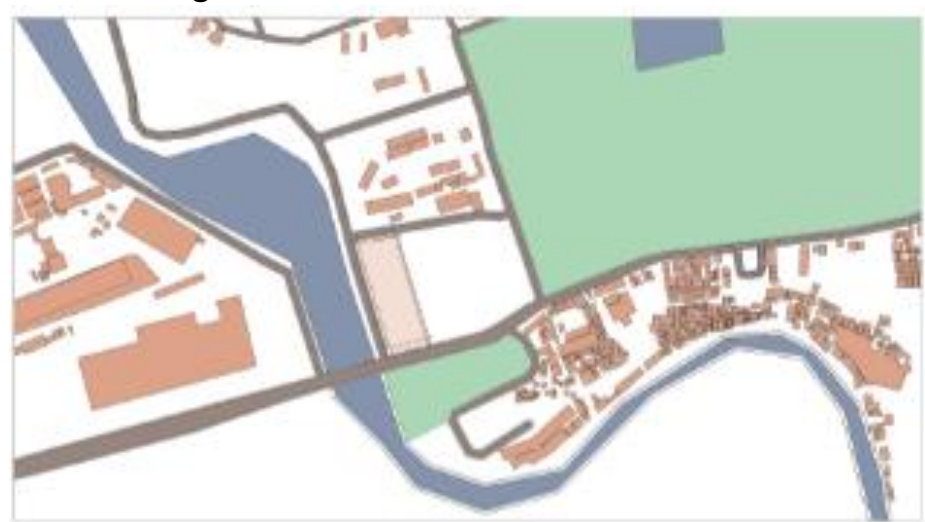

Gambar 8. Lokasi Site Terpilih Marunda

Kawasan pengamatan merupakan suatu kawasan yang memiliki potensi besar untuk dijadikan daerah wisata. Letaknya yang strategis, dekat dengan pelabuhan, peninggalan Betawi salah satunya seperti rumah Pitung dan ruang terbuka hijau dekat lokasi. menjadi salah satu tempat singgahan yang dapat dikunjungi

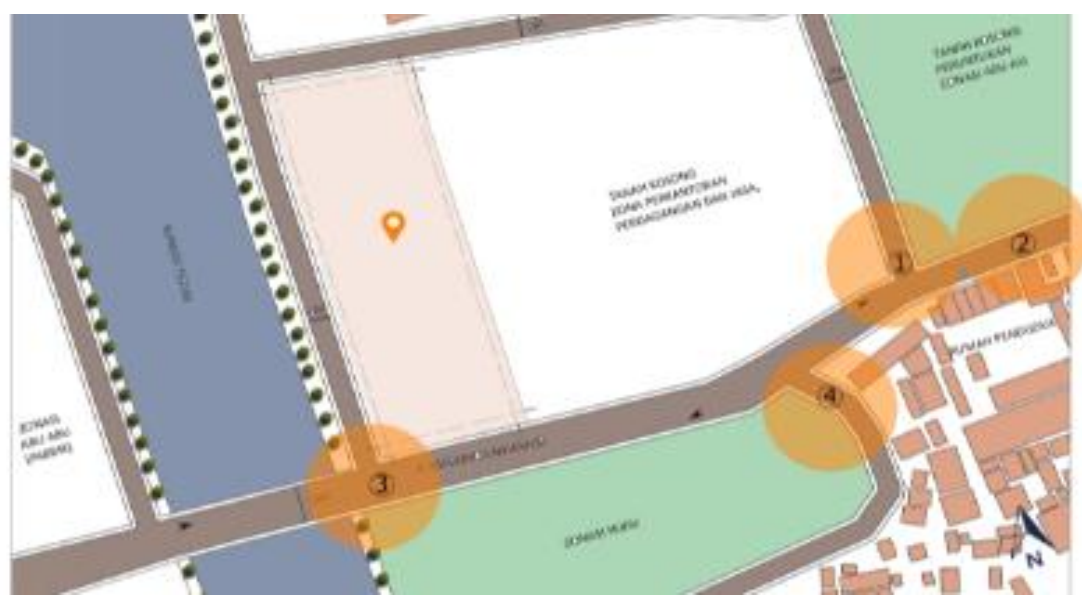

Gambar 9. Akses Site Kawasan Marunda 
- Lokasi berada di dekat lingkungan Betawi, lokasi berdekatan dengan bangunan yang memiliki fungsi kebudayaan atau Kawasan yang memiliki kaitan terhadap suku Betawi sehingga bangunan dapat berbaur dan mendukung kegiatan yang ada sebelumnya.

- Lokasi memiliki daya Tarik bagi wisatawan serta lokasi mudah dikenal dan dituju. Lokasi terletak berdekatan dengan pusat hiburan dan wisata, lokasi didukung dengan adanya kemudahan pencapaian tapak berupa jalur pelestarian yang nyaman, jalan ramai dilalui kendaraan angkutan umum dan dekat dengan haalte, stasiun atau terminal yang memudahkan pengunjung untuk memperoleh kendaraan bagi pengunjung dalam radius yang lebih jauh.

- Lokasi menunjang adanya fungsi komersil, funjgsi komersil yang telah ada sebelumnya mendukung tapak yang akan dibangun sebagai penarik pengunjung yang akan dating ke bangunan yang memiliki fungsi komersil.

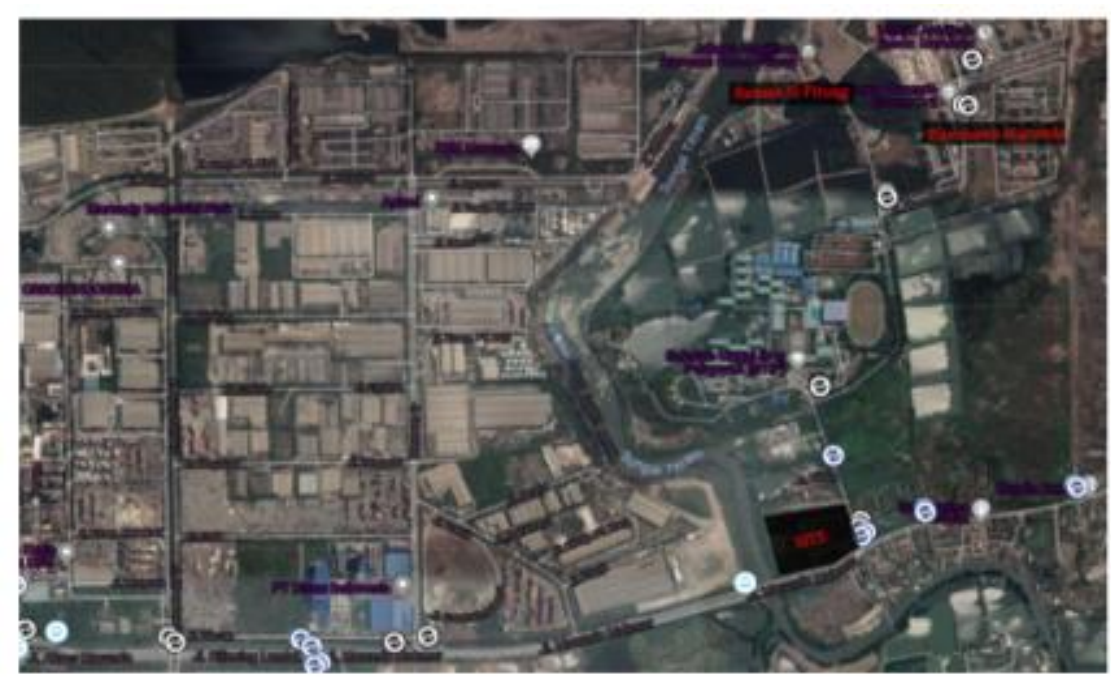

Gambar 10. Jalur Transportasi Umum Tapak Sumber: Google Map Marunda

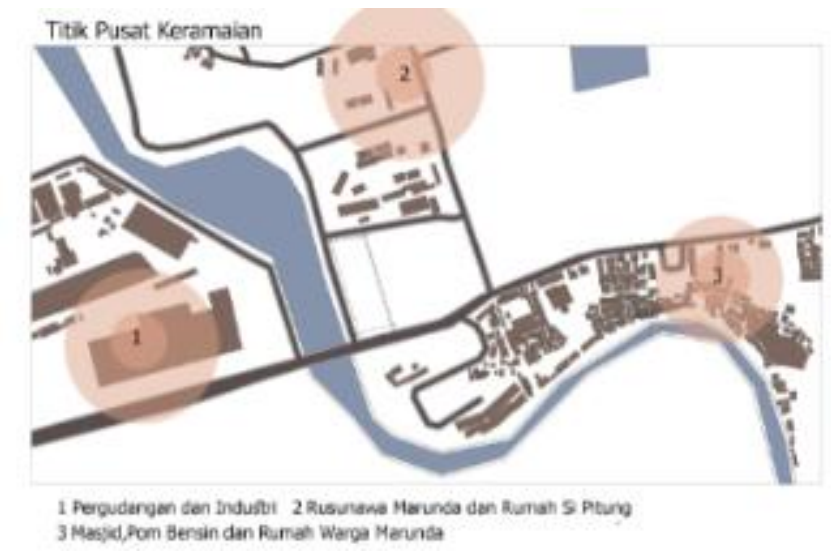

Gambar 11. Titik Pusat Keramaian

Titik pusat keramaian pada kawasan Marunda merada pada 3 titik yang menjadi pusat kunjungan yang pertama kegiatan industri dan pergudangan yang keluar masuk melewati jalur utama, pada titik kedua berada di pusat wisata di Marunda yaitu rumah Si Pitung yang menjadi kunjungan tiap wisatawan yang berada di Marunda, pada titik ketiga berada di masjid dan fasilitas umum yang sering di gunakan oleh warga sekitar Marunda ketika berkunjung. 


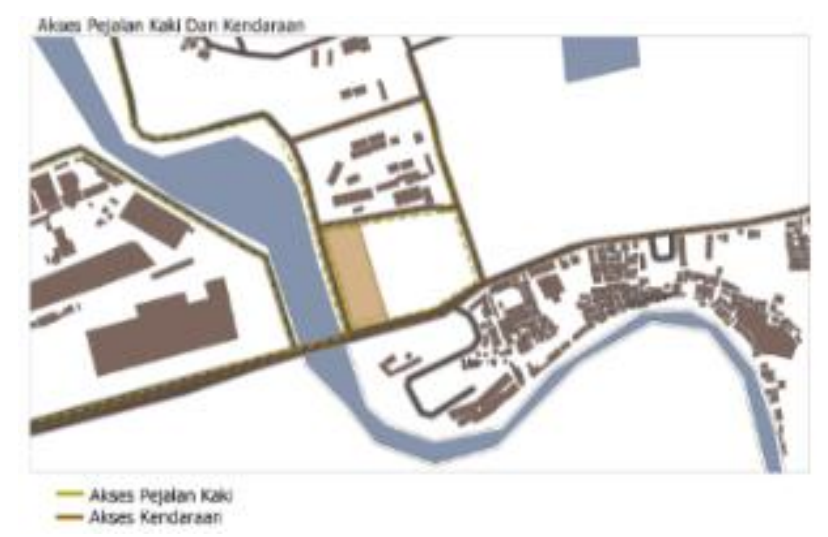

Gambar 12. Akses manusia dan Kendaraan

Kawasan Marunda memiliki beberapa akses yang dapat di tempuh menggunakan jalan kaki dan juga kendaraan yang nantinya akan menjadi prinsip dan juga masalah yang akan di pecahkan pada saat pemilihan site yang tepat di Kawasan Marunda..

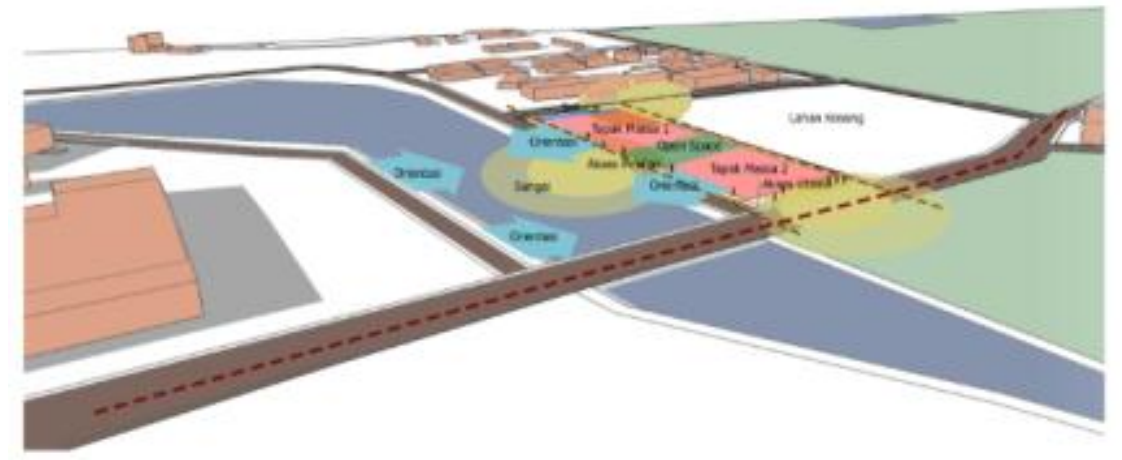

Gambar 13. Perencanaan Lahan Pada Site

Dari Analisa seluruh kegiatan pada program ruang, kemudian ditentukan hubungan dan sirkulasi ruang sebagai berikut, dimana terdapat plaza utama yang menggabungkan seluruh fungsi tersebut, penggambaran bubble diagram sirkulasi ruang secara garis besar.
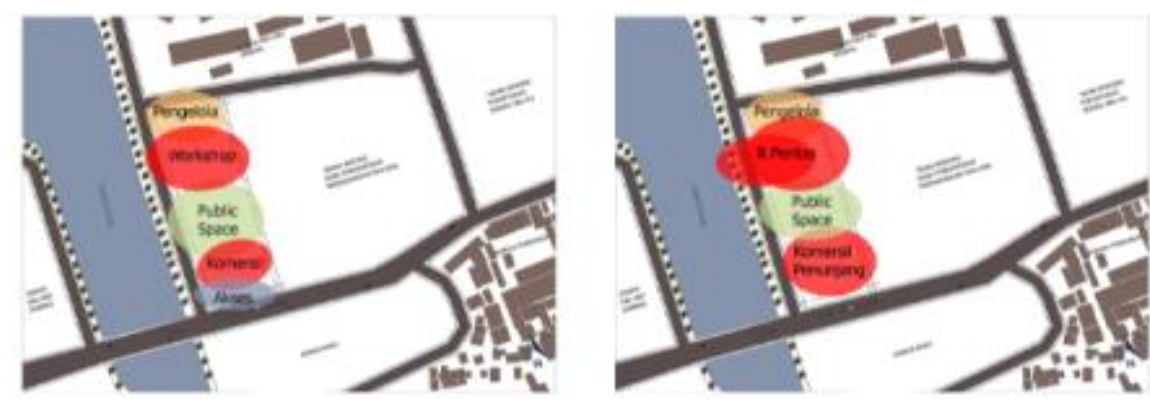

Gambar 14. Perencanaan Secara Makro

Konsep ruang yang dipakai juga bedasarkan pada rumah rumah tradisional Betawi dimana pengunjung terlebih dahulu disambut di serambi, serambi pada rumah Betawi selalu menjadi ruang public/komunaal tempat para tamu dengan penghuni rumah saling belajar, bertukar ide dan bercanda gurau. Begitu juga dengan konsep disediakan serambi yang digunakan untuk menerima pengunjung dan wisatawan baru mereka akan menulusuri zona-zona yang lain seperti Teater, Food area, Sanggar, Workshop dan lain-lain. 


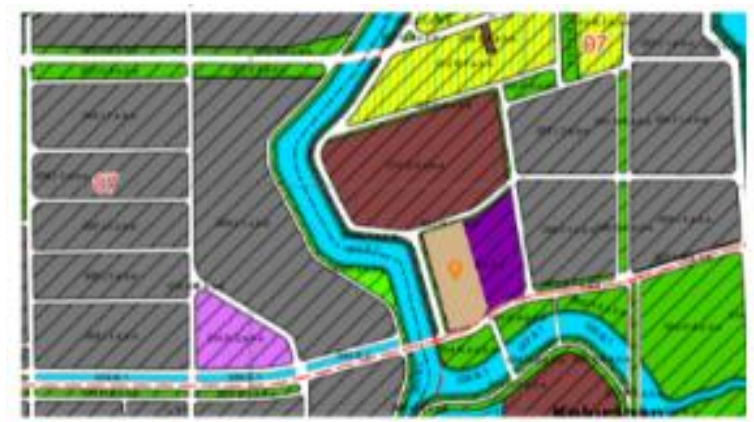

Gambar 15. Peruntukan di Marunda Sumber: Tata Ruang Jakarta
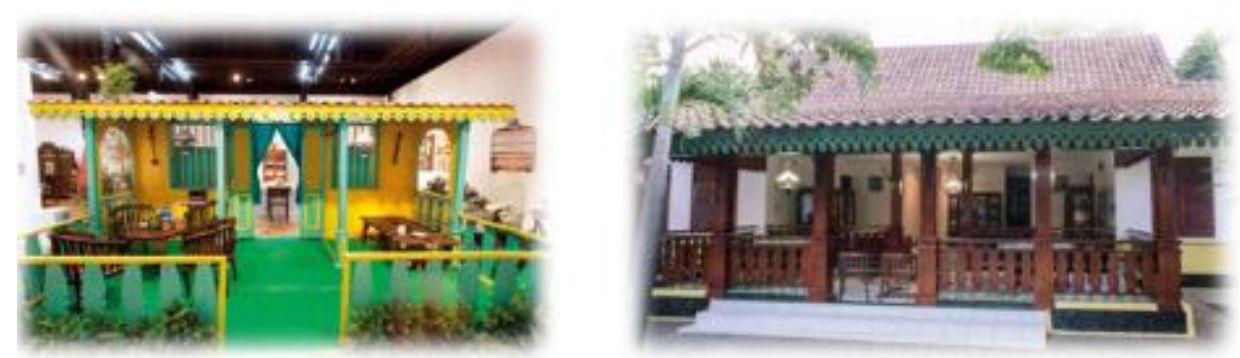

Gambar 16. Rumah Tradisional Betawi

Sumber: tribunnews.com

Pada site di Marunda yang terletak di jalan Marunda Makmur, dengan peruntukan campuran dan industri di kawasan Marunda, pada tapak atau site memiliki KDB:50 KLB :2.00 KB:4 KDH:35 KTB:50 dengan luas lahan $7.000 \mathrm{~m}^{2}$ dengan keadaan lahan masi kosong dan memiliki akses transportasi umum yang mudah untuk menuju site selain itu juga memiliki jalan akses yang dekat dengan destinasi wisata Rumah Si Pitung yang bisa di katakan sebagai icon Betawi di Marunda.

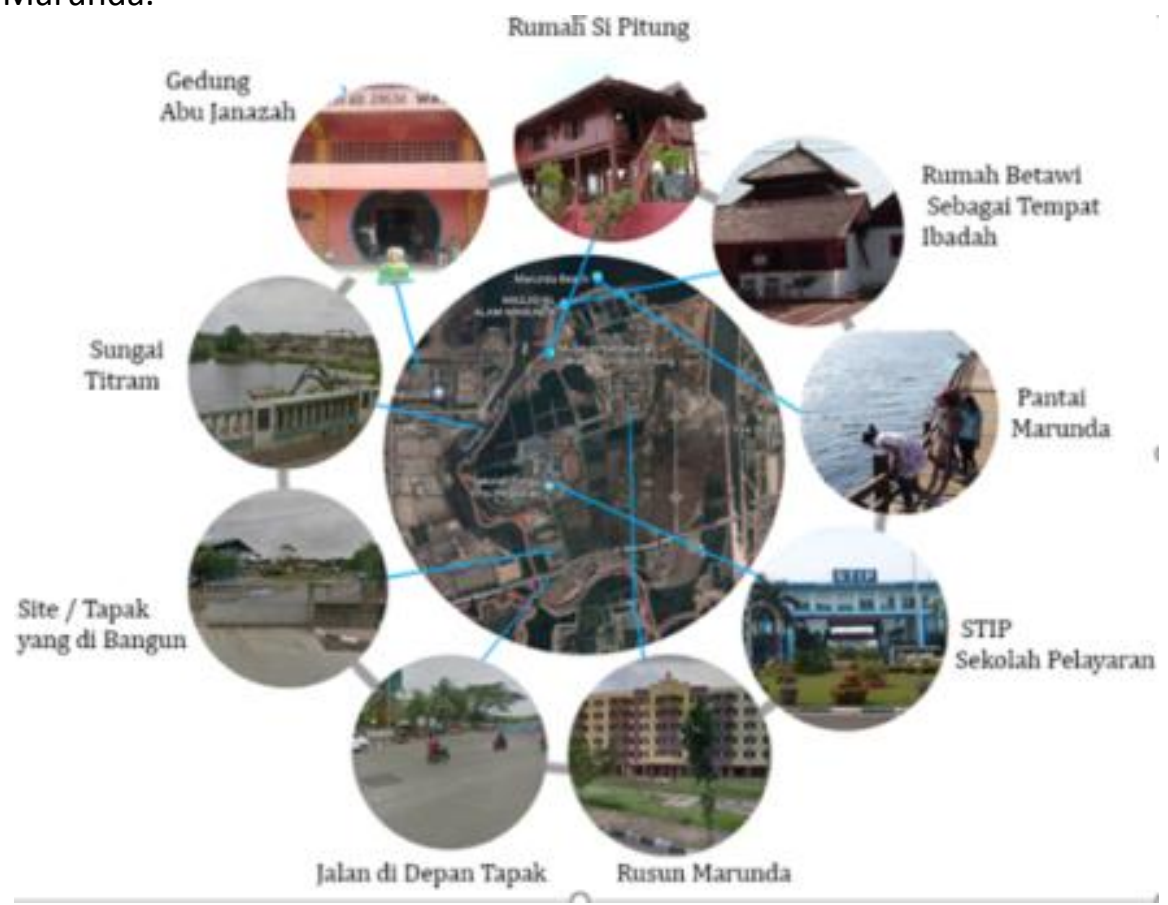

Gambar 17. Data Lapangan Sekitar Site di Marunda 


\section{KESIMPULAN DAN SARAN}

Terdapat kesimpulan dari pembuatan proyek yang berada di Marunda, Jakarta Utara yang kurang berkembang dan masi banyaknya wagra asli Betawi yang menetap di Marunda, untuk melestarikan kebudayaan Betawi yang mulai punah pada kawasan Marunda yang identik dengan warga asli Betawi yang masi menetap dan mendirikan bangunan untuk pertunjukan kesenian kebudayaan Betawi dengan tujuan memperkenalkan kembali kebudayaan yang sudah mulai menghilang dan membangkitan kesadaran masyarakat terhadap kebudayaan Betawi yang perlu di lestarikan dan mengambil kembali identitas Jakarta yang erat dengan kebudayaan Betawi.

Semakin banyak kebudayaan Betawi yang tidak dapat kita pertahankan itu akan menjerumuskan kepada hilangnya budaya Betawi untuk masa depan.

Area Marunda terkenal dengan area industrinya, dengan itu kita mendapatkan akses yang jelas lebih mencukupi ddibanding area perumahan biasa atau perkantoran biasa. Tanpa mengganggu aktivitas industri, proyek ini justru akan menigkatkan daya tarik dari cara ini yang ternyata memiliki nilai kebudayaan yang cukup kental dan dapat menjadi alternatif maskot kawasan.

Nantinya kawasan yang menjadi pusat kebudayaan Betawi akan mewadahi dan menampung semua kegiatan kesenian Betawi yang tidak memiliki wadah untuk berekspresi di Jakarta, dengan mempertimbangkan kegiatan yang akan terbentuk pada pusat kebudayaan Betawi maka sasaran pengunjung diharapkan dapat datang dari semua golongan tidak hanya pelajar atau seniman dan budayawan, tetapi dapat mencakup masyarakat luas. Karena diharapkan bangunan ini dapat menjadi titik awal dari bangunan sejenis yang mengusung tema kebudayaan modern. Pada desain bangunan Betawi Milenial konsep modern dan teknologi pada bangunan sangat di tonjolkan tanpa melupakan konsep dari kebudayaan Betawi tradisional dan memberikan kesan yang berbeda dari pertunjukan kesenian lain yang sudah ada mereka hanya mempertontonkan tanpa melakukan interaksi pada penonton. Nantinya diharapkan bangunan kesenian Betawi ini dapat dinikmati oleh semua kalangan dan meningkatkan kawasan Marunda dari segi perekonomian dan pariwisata kebudayaan.

\section{REFERENSI}

Chaer, Abdul. (2012). Folklor Betawi: Kebudayaan dan Kehidupan Orang Betawi. Jakarta: Masup Jakarta.

Shahab, Yasmine. (1997). Betawi dalam Perspektif Kontemporer. Jakarta: Lembaga Kebudayaan Betawi.

Specht, Jan. (2014). Architectural Tourism. Springer Gabler

Sucipto, Toto. (2006). Profil Kebudayaan Betawi, Bandung: Deapartemen Kebudayaan dan Pariwisata

Swadarma, Doni. (2013). Rumah Etnik Betawi. Depok: Griya Kreasi

Zahnd, Markus. (1999). Perancangan kota secara terpadu. Yogyakarta : Kanisius

The Bilbao Effect : How Frank Gehry's Guggenheim Started a Global Craze

https://www.theguardian.com/artanddesign/2017/oct/01/bilbao-effect-frank-gehry-

guggenheim-global-craze

BPS. 2016. Jakarta dalam Angka 2016 dari BPS:

https://jakarta.bps.go.id/backend/pdf_publikasi/Jakarta-Dalam-Angka-2016.pdf

BPS. 2017. Statistik Daerah Kecamatan Cilincing 2017:

https://jakutkota.bps.go.id/publication/2017/09/26/c4286976b0a7bc5632af43fd/kecamatancilincing-dalam-angka-2017.html

www.theguardian.com The Bilbao Effect : How Frank Gehry's Guggenheim Started a Global Craze

https://www.archdaily.com/599263/construction-begins-on-open-s-pingshan-performing-

arts-center-in-shenzhen 
https://www.archdaily.com/565413/shenzhen-performing-arts-facility-zoboki-demeter-andassociates

https://www.archdaily.com/437545/sejong-center-for-performing-arts-asymptotearchitecture

https://www.archdaily.com/353853/performing-arts-studio-of-the-national-theatre-of-koreasecond-prize-winning-proposal-archiplan

https://www.archdaily.com/65218/ad-classics-sydney-opera-house-j\%25c3\%25b8rn-utzon https://www.archdaily.com/518954/akiha-ward-cultural-center-chiaki-arai-urban-andarchitecture-design

https://www.archdaily.com/555446/theatre-de-stoep-unstudio 